\title{
COMPARATIVE STATISTICAL TABLES
}



ลิธ

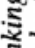

ริ

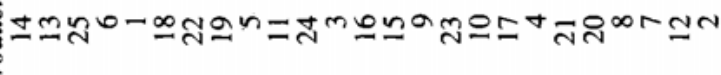

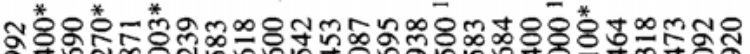

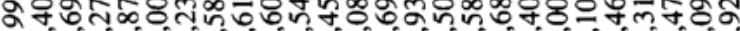

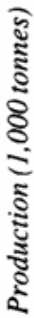

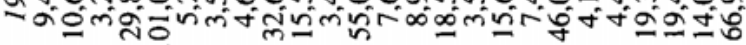

a
ñ
๘

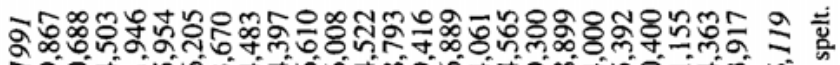

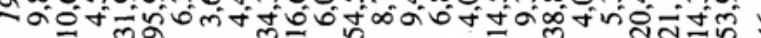

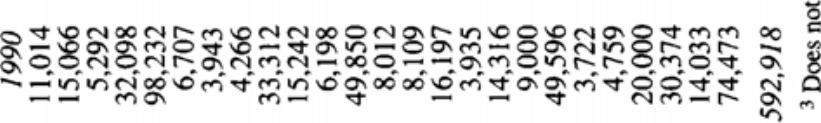

:

잉 $\infty$ \%

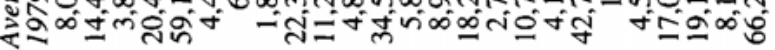

**

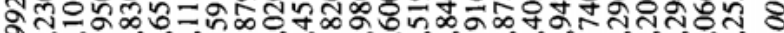

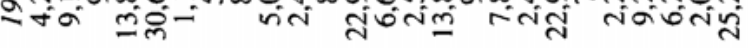

กิ

ฐิ

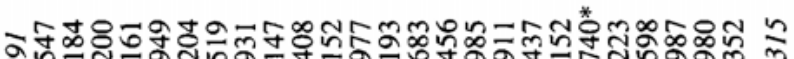

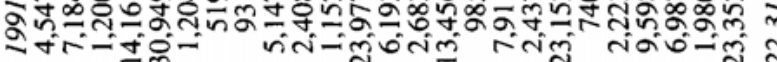

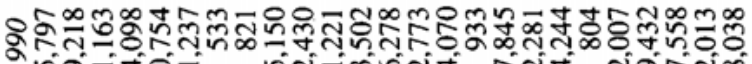

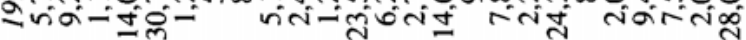

స̃

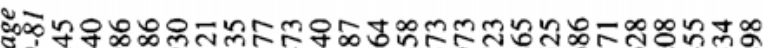

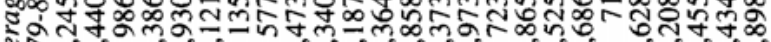

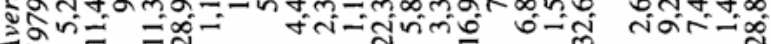

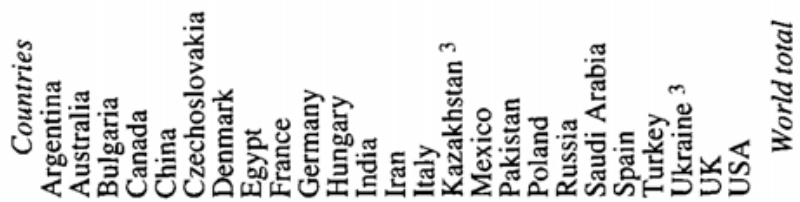


ลิธ

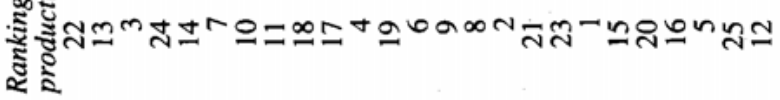

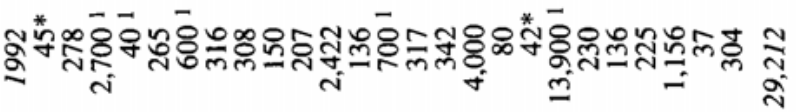

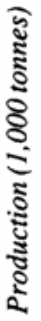

হूँ

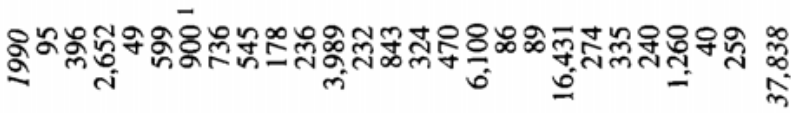

:

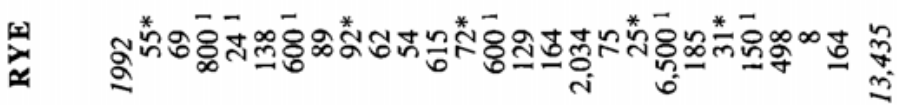

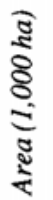

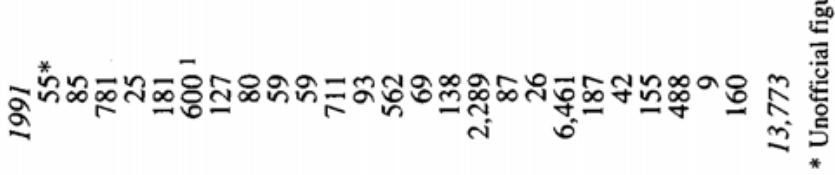

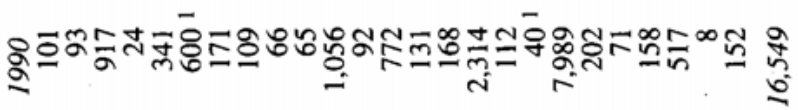

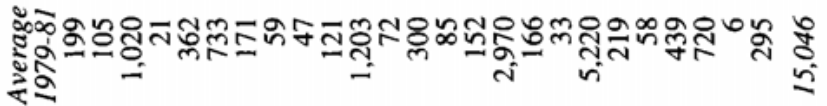

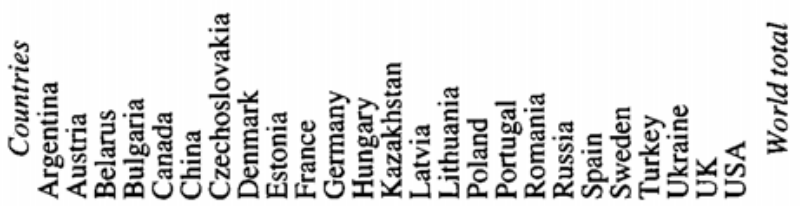




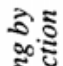

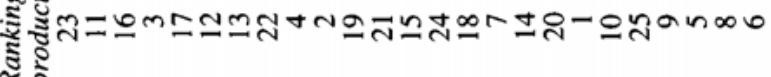

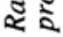

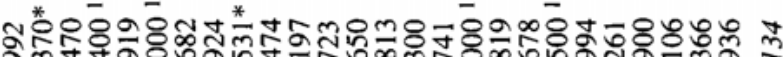

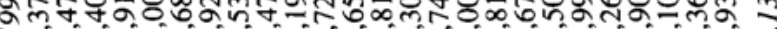

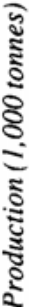

-

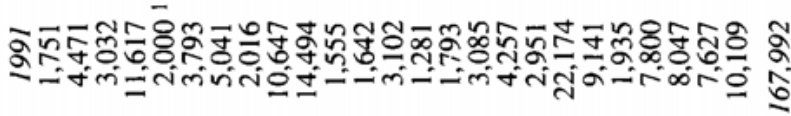

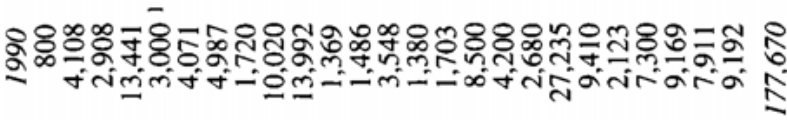

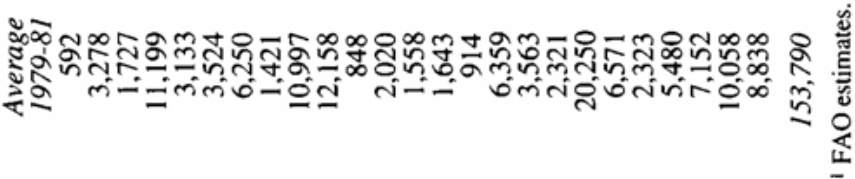

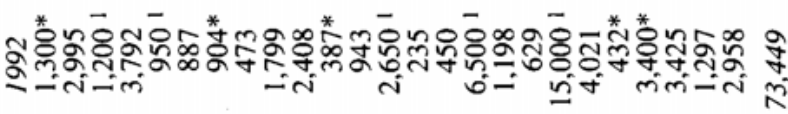

$\frac{2}{2}$

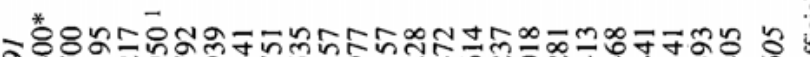

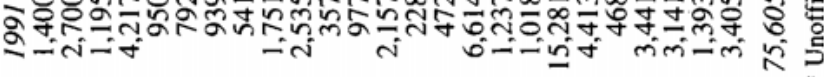

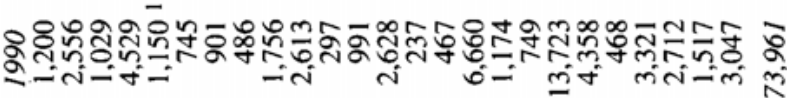

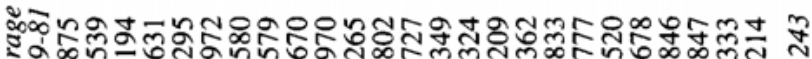
ఫूर

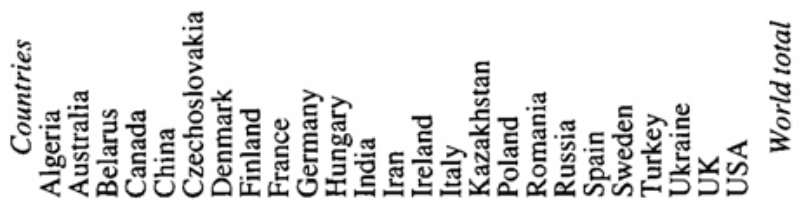


ลิธ

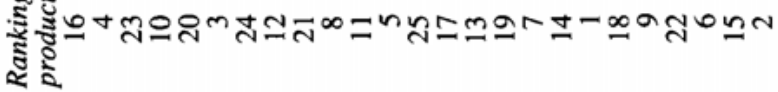

๙

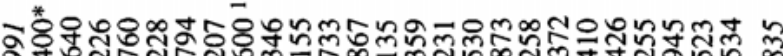

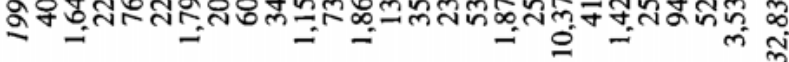

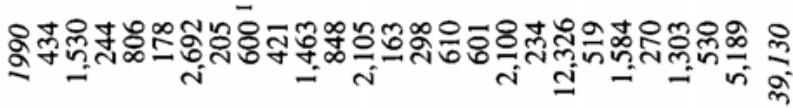

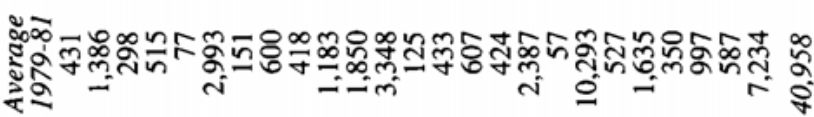

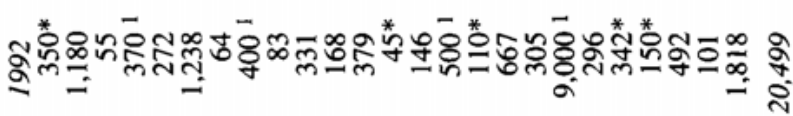

$\frac{\pi}{3}$

Бํำ

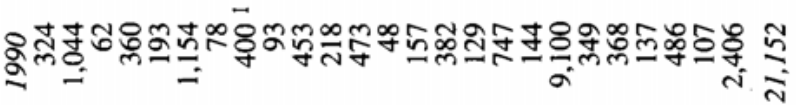

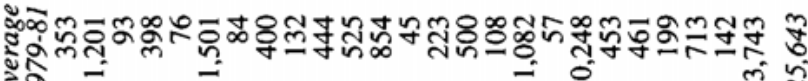
خू - - 0 की

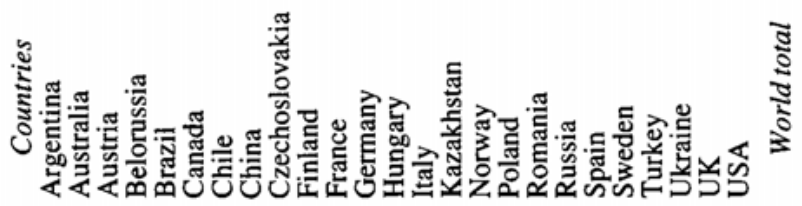


35

o

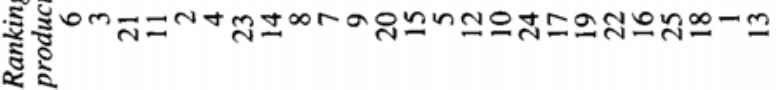

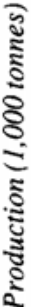

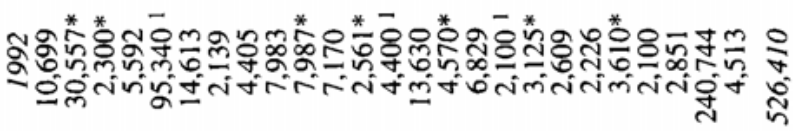

-

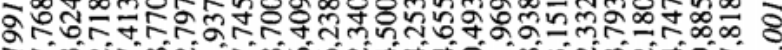

-

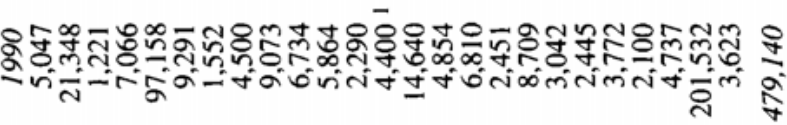

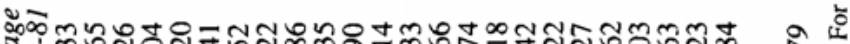

इล่

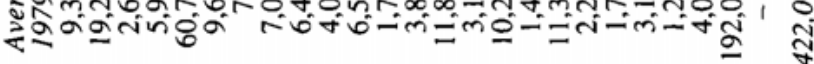

$\stackrel{\text { 뇐 }}{2}$

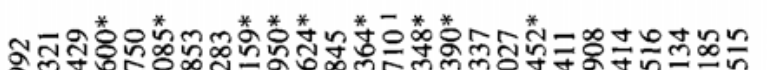

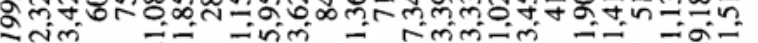

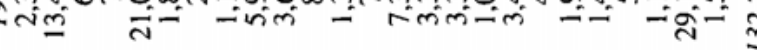

$\frac{\sqrt{2}}{8}$

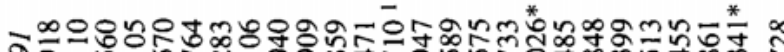

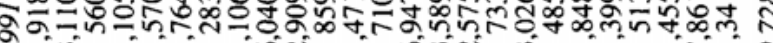

$-m=-1=-6$ -

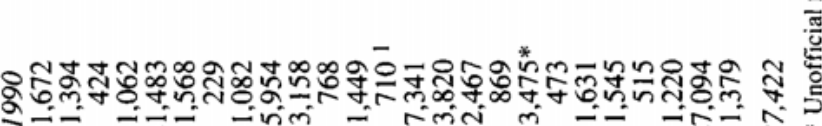

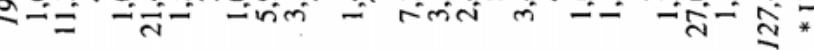

:

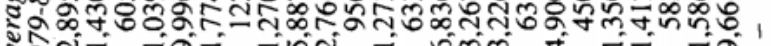

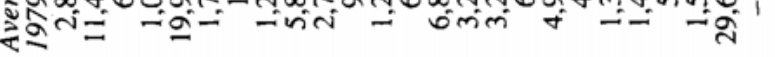


วิธ

胥范

起交

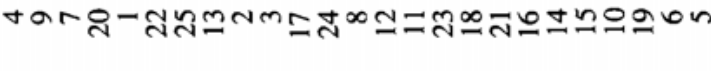

ปัँ

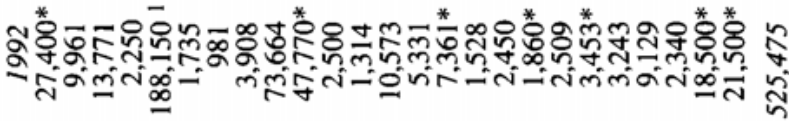

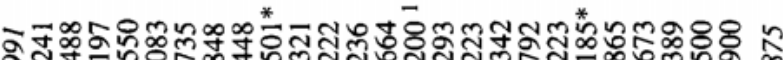
ส가

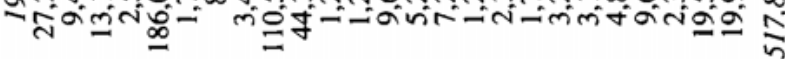

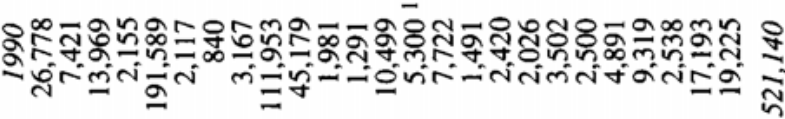

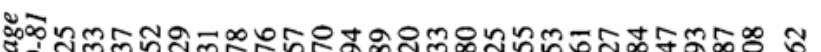

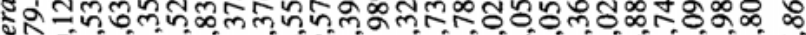

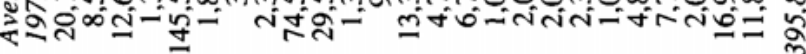

홇

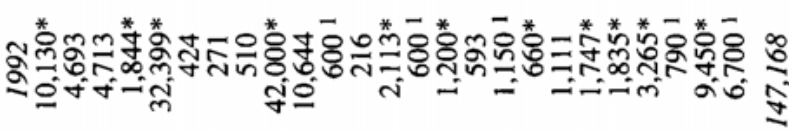

$\frac{8}{8}$

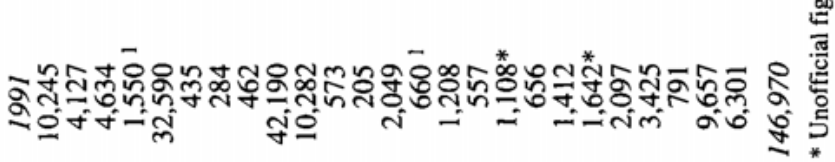

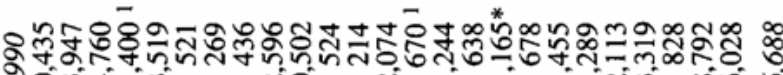

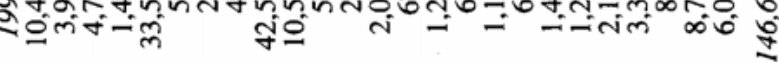

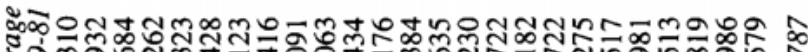
รด่

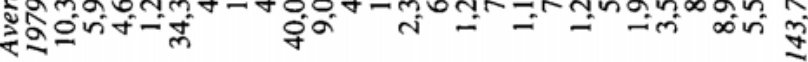

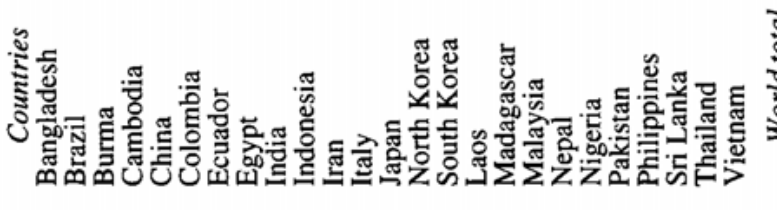


จิธี

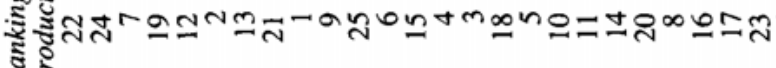
¿

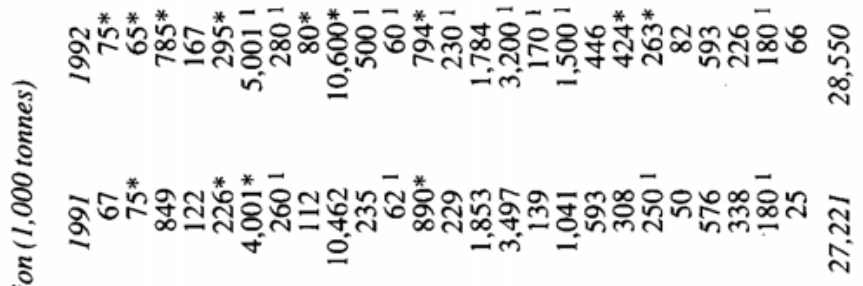

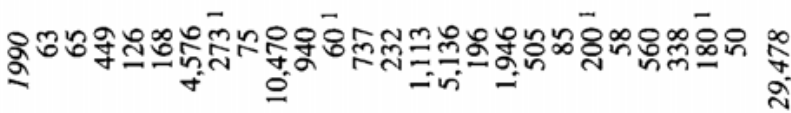

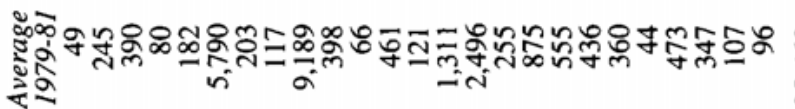

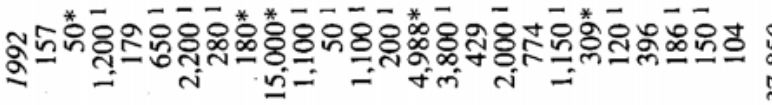

$\frac{\pi}{8}$

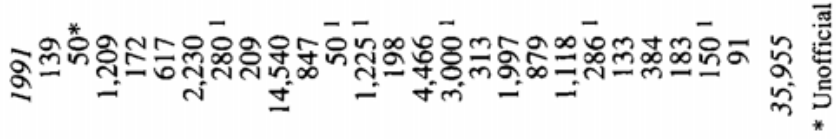

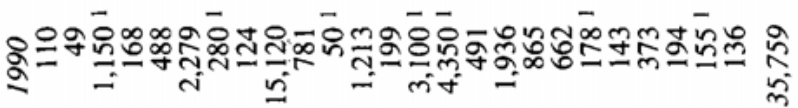

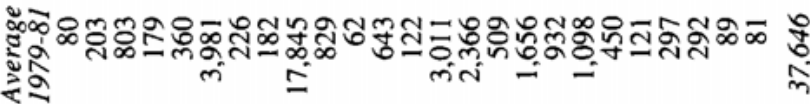

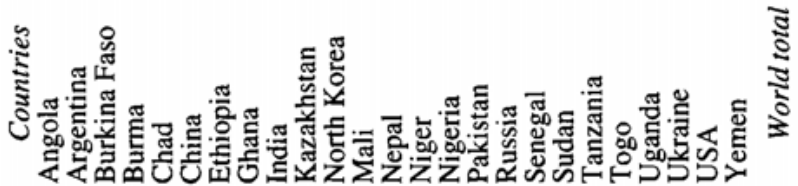


จิธี

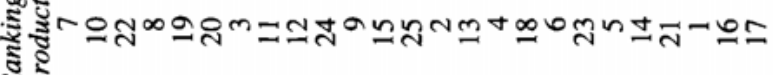
路

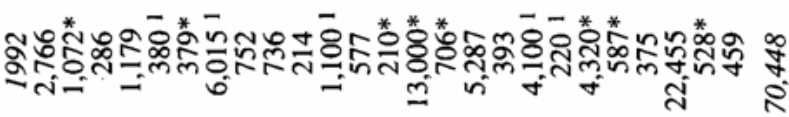

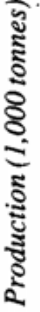

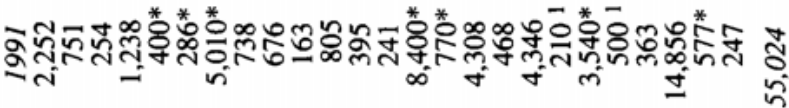

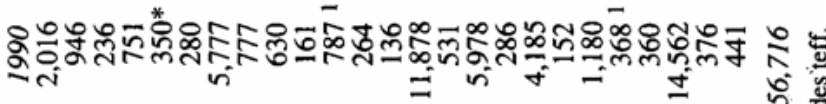
$=n$ 政

ฌळ-

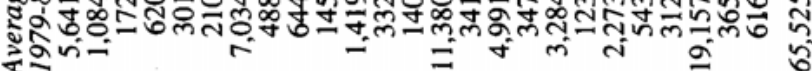

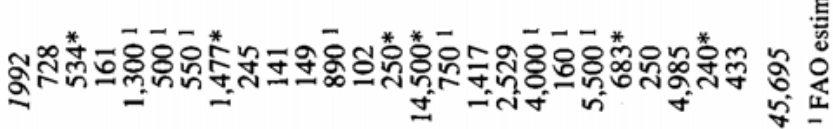

$\frac{\pi}{3}$

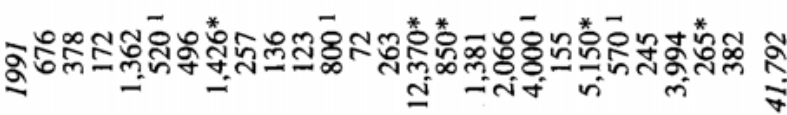

๙ิ

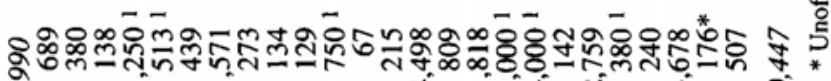

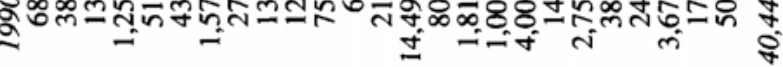

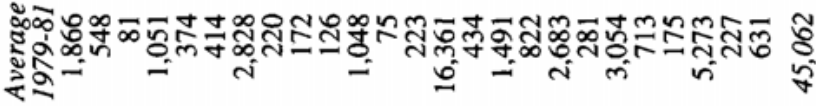

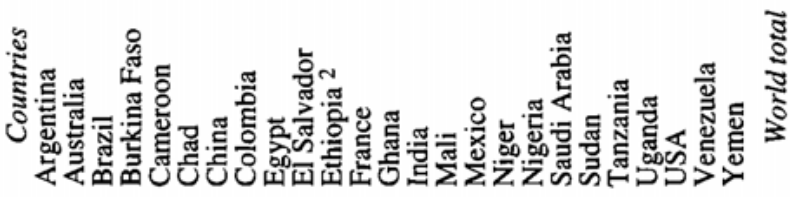


xxvii

CENTRIFUgal RAW SUGAR

(in 1,000 tonnes)

\begin{tabular}{l}
\multicolumn{1}{c}{ Countries } \\
Argentina \\
Australia ${ }^{\text {1 }}$ \\
Belgium-Luxembour \\
Brazil \\
Chile \\
China \\
Colombia \\
Cuba \\
Czechoslovakia \\
Dominican Republic \\
Egypt \\
France \\
Germany \\
Guatemala \\
India ${ }^{3}$ \\
Indonesia 2 \\
Iran \\
Italy \\
Japan \\
Mauritius \\
Mexico \\
Netherlands \\
Pakistan ${ }^{3}$ \\
Philippines \\
Poland \\
Russia \\
South Africa \\
Spain \\
Sudan \\
Thailand \\
Turkey \\
Ukraine \\
UK \\
USA \\
Venezuela \\
$\quad$ World total \\
\end{tabular}

Average
1979-81

$\begin{array}{ll}1990 & 1991 \\ 1,351^{*} & 1,570^{*} \\ 3,515 & 3,290^{*} \\ 1,146 & 968^{*} \\ 7,835^{*} & 9,238^{*} \\ 343 & 334 \\ 7,396^{*} & 9,075^{*}\end{array}$

Ranking by

1,584

3,243

994

7,991

131

3,855

1,192

7,510

1,589

1,702

808

1,142

$8,445^{*}$

$7,623^{*}$

686

590

971*

714

584

4,720

4,744

3,936

4,671

839
11,945

409

5,380

2,075

626*

$1,586^{*}$

1,956

789

866

982*

4,423

4,675

918

12,940

2,215

799*

$1,640 *$

923

615

624

611

2,780

3,278

1,000

1,304*

$3,365 *$

$1,137 *$

$2,017 *$

2,342

$1,810^{*}$

$2,100 *$

$1,736 *$

1,677

1992

$1,300^{*}$

4,260*

966*

9,500*

486

$8,870^{*}$

1,989

6,900

$680 *$

610*

$950^{*}$

$4,735^{*}$

4,373

943

$14,400^{*}$

1,659

$870^{*}$

$2,010^{*}$

987

643

$3,574 *$

1,304*

$2,528 *$

$2,081 *$

$1,520^{*}$

$2,360 *$

$2, \overline{11}$

934

$-$

$2,391 *$

$2,226 *$

994

421*

2,028 *

166

1,534

3,506

951

471*

1,178

$1,946 *$

4,055

5,360*

$1, \overline{2} 15$

1,349

2,052 *

$3,600^{*}$

5,345

344

6,263

499

1,326

6,558

$542 *$

$1,800^{*}$

1,047*

513*

$5,106 *$

$1,957 *$

$3,850 *$

1,603

6,985

$567 *$

production

88,774

111,270

112,243

115,939

* Unofficial figures.

$194^{\circ}$ net titre.

$2 \mathrm{Tel}$ quel.

${ }^{3}$ Includes sugar (raw value) refined from gur. 


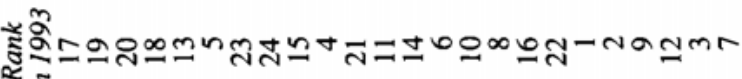

..

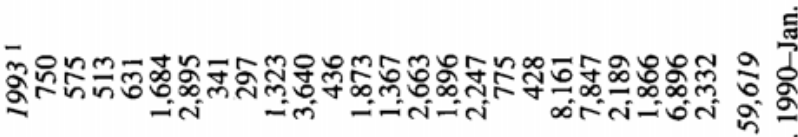

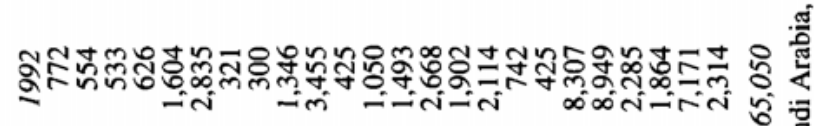

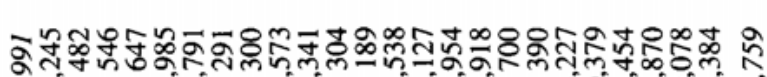

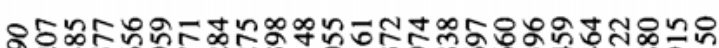

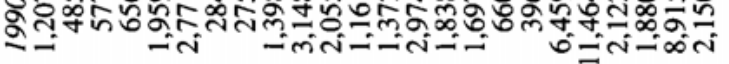

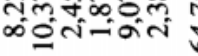

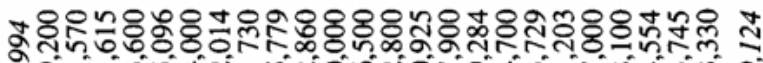

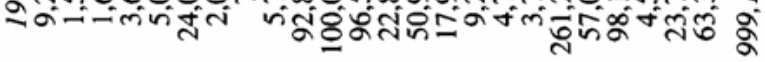

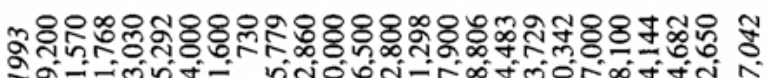
2.

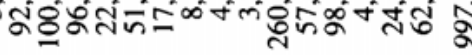

